\title{
Data Mining Prediksi Minat Customer Penjualan Handphone dengan Algoritma Apriori
}

\author{
Sri Wahyuni ${ }^{1}$, Indri Sulistianingsih ${ }^{2}$, Hermansyah $^{3}$, Eko Hariyanto ${ }^{4}$, \\ Oki Cindi Veronika Lumbanbatu ${ }^{5}$ \\ 1) Teknik Komputer, Universitas Pembangunan Panca Budi \\ 2), 3), 4), 5) Sistem Komputer, Universitas Pembangunan Panca Budi \\ Email: sriwahyuni@dosen.pancabudi.ac.id,
}

\begin{abstract}
ABSTRAK
Mengetahui minat customer pada suatu jenis produk merupakan kunci suskses dari sebuah bisnis. dari data yang tersimpan pada data penjualan dapat diolah dan diimplementasi untuk mengetahui pola minat item customer, hal ini dapat meminimalisir penumpukan stok barang yang kurang diminati dan tidak kehabisan barang pada produk yang diminati. Data Mining dapat menjadi solusi. Penelitian ini menganalisis data informasi penjualan handphone yang bersumber dari database sistem informasi transaksi penjulanan handphone menggunakan data mining algoritma apriori. Uji data menggunakan aplikasi data mining weka dalam menemukan hubungan pola penjualan handphone antar item. Proses pengolahan data dimulai praprocesing dengan memilih variable data kemudian menemukan nilai spot dari tiap item set handphone dan kombinasi antara jenis handphone dari hasil pencarian nilai spot dan kombinasi antara jenis handphone kemudian ditemukan nilai confidence dalam tiap kombinasi. Kombinasi yang memenuhi nilai minimum spot dan minimum confidence akan menjadi sebuah aturan asosiasi. Aturan asosiasi yang dihasilkan menjadi informasi jenis handphone yang paling banyak terjual selama 1 bulan sampai 2 tahun. Hasilnya di peroleh knowlwge jenis handphone yang paling diminati dan hubungan antara jenis atau tipe hanphone tersebut. Knowledge tersebut dapat dijadikan dasar menentukan stok jenis handphone.
\end{abstract}

Kata kunci: data mining, algoritma apriori, knowlege, penjualan handphone, confidence

\begin{abstract}
Knowing the customer's interest in a type of product is the key to the success of a business. From the data stored in sales data, it can be processed and implemented to find out patterns of customer interest in items, this can minimize the accumulation of stock of items that are less desirable and do not run out of items in the products of interest. Data Mining can be a solution. This study analyzes data on mobile phone sales information sourced from a database of cellphone sales transaction information systems using a priori algorithm data mining. Test the data using the Weka data mining application in finding the relationship between the pattern of cellphone sales between items. The data processing process begins with preprocessing by selecting data variables and then finding the spot value of each item set of cellphones and the combination of types of cellphones from the search results for spot values and combinations of types of cellphones then finding the confidence value in each combination. The combination that meets the minimum spot value and minimum confidence will be an association rule. The resulting association rules become information on the type of cellphone that is sold the most for 1 month to 2 years. As a result, knowledge of the type of cellphone that is most in demand and the relationship between the type or types of cellphones is obtained. This knowledge can be used as the basis for determining the type of cellphone stock.
\end{abstract}

Keywords: data mining, apriori algorithm, knowledge, mobile phone sales, confidence 


\section{Pendahuluan}

Penumpukan jumlah data dari suatu sistem dapat digali dan diolah menjadi informasi yang sangat berharga (Wahyuni, Saragih and Perangin-angin, 2018), (Ashraf, Anwer and Gufran, no date) (Li et al., 2012). Data mining juga dapat di terapkan dalam bidang penjualan (Wahyuni, Suherman and Harahap, 2018). Untuk mendapatkan keuantungan yang maksimal maka dibutuhkan suatu cara dalam meminimalisir angka kerugian yaitu meminimalkan stok produk yang kurang diminati dan memaksimalkan stok produk yang diminati konsumen. Data mining dapat menjadi solusi dalam permasalahan predisi stok penjualan (Sianturi, Informatika and Utara, 2018). CV. Polindo merupakan sebuah perusahaan yang bergerak dibidang penjualan handphone baik itu jenis produk handphone Android, Iphone dan berbagai jenis hanphone lainnya. Penjualan dilakukan menggunakan sistem informasi penjualan handphone yang sudah memiliki database, ini merupakan suatu keunggulan dalam memperoleh data transaksi penjualan hanphone. Namun dalam memanajemen persedian stok barang belum menggunakan suatu sistem dan metode yang tepat sehingga masih terdapat kesulitan dalam menentukan produk handphone dan aksesoris apa saja yang sering dibeli oleh konsumen juga belum terungkapnya keterkaitan suatu produk handphone atau aksesoris yang satu dengan yang lainnya. Data mining dapat menjadi solusi dari permasalahan yang dihadapi sehingga penambahan persediaan produk ataupun pengurangan persedian suatu produk dapat lebih aku-rat dan meminimalisir stok yang tidak laku terjual, yang tidak kalah penting manajemen pemasaran bisa lebih maksimal menerapkan strategi pemasaran pada suatu produk yang kurang diminati.

Menggunakan data transaksi penjualan produk handphone yang di peroleh dari database sistem in-formasi penjualan handphone dengan memperoleh rule dan knowledge yang dapat dijadikan dasar pengabilan strategi dan keputusan, hal ini mendorong pemanfaatan cabang ilmu data mining dalam mengatasi masalah penggalian informasi atau pola yang penting atau menarik dari data dalam jumlah besar, yang disebut dengan data mining (Wahyuni, Saragih and Perangin-angin, 2018), (Ezhilarasan and Ramani, 2018), (Yu et al., 2019). Pengunaan teknik data mining diharapkan dapat mem-berikan pengetahuan yang sebelumnya tersembunyi di dalam gudang data se-hingga menjadi informasi yang berharga, dari beberapa algoritma yang ada pada data mining akan dipilih algoritma Apriori sebagai langkah dalam menghasilkan knowledge.

Persediaan produk handphone selama ini sering kali tidak mampu memenuhi permintaan pelanggan sebagaimana mestinya, sehingga membuat kekecewaan para konsumen serta hilangnya minat dalam membeli handphone. Untuk mengatasi permasalahan dalam tata kelola persediaan produk handphone tersebut dapat dilakukan dengan menggunakan teknik analisis keranjang belanja atau Market Basket Analysis (MBA) yaitu analisis dari kebia-saan membeli konsumen dan algoritma Apriori (Ezhilarasan and Ramani, 2018), (Jaya and Hanadwiputra, 2021). Analisis ini merupakan metode dalam penambangan data (data mining) yang bertujuan untuk menentukan produk-produk yang sering dibeli bersa-maan dari data transaksi (Muchlis, Fitri and Nuraini, 2021). Untuk membantu proses mining maka dilakukan suatu pengujian dengan aplikasi weka dengan cara penguraikan data dalam bentuk excel dan memilih proses upload untuk input data awal (Br Ginting, 2021). Setelah proses selesai maka dilakukan proses pembentukan mining dan terbentuk rule terbaik berdasarkan data hasil uji coba (Ezhilarasan and Ramani, 2018). 


\section{Metode Penelitian}

Framework dilakukan secara bertahap. Berikut framework penelitian ditunjukan pada gambar 1 sebagai berikut :

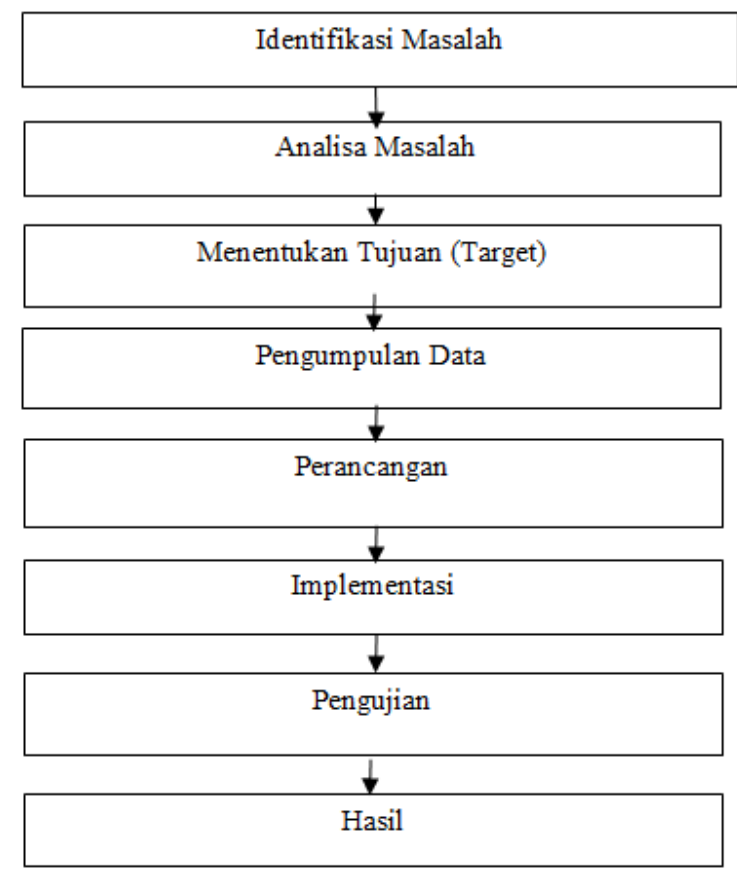

Gambar 1. Framework Penelitian

\section{Identifikasi Data Transaksi}

Identifikasi data dilakukan setelah data terkumpul dan sesuai dengan kebutuhan sistem. Kesimpulan yang dihasilkan berdasarkan aturan (rule) pada analisis data diperlukan data transaksi yang telah dilakukan. Analisis data tersebut dilakukan berdasarkan teknik aturan asosiasi menggunakan algoritma apriori dengan beberapa iterasi atau langkah-langkah. Data yang diambil merupakan data penjualan pada bulan 01 Januari 2020 sampai dengan 31 Januari 2020.

\section{Analisis Pencarian Pola Frekuensi Tinggi}

Dari tabel 1.dilakukan perhitungan nilai frekuensi berdasarkan 29 data penjualan dan kemudian dilakukan pencarian nilai support dengan rumus :

$$
\text { Support }(A)=\frac{\text { Jumlah Transaksi Mengandung } A}{\text { Total Transaksi }} \times 100 \%
$$

\section{Pembentukan Pola Kombinasi Dua Itemset}

Pembentukan pola frekuensi 2-itemset dibentuk dari item-item produk yang memenuhi Minimum Support yaitu dengan cara mengkombinasikan semua item kedalam semua pola kombinasi 2-itemset kemudian hitung nilai support-nya dengan rumus:

$$
\text { Support }(A \cap B)=\frac{\text { Jumlah Transaksi Mengandung A dan B }}{\text { Total Transaksi }} \times 100 \%
$$




\section{Pembentukan Aturan Asosiasi (Association Rule)}

Untuk mencari aturan asosiasi terhadap langkah-langkah yang dilakukan sebelumnya, kemudian akan dihitung nilai confidence dari setiap item berdasarkan rumus.

$$
\text { Confidence }=P(A \mid B)=\frac{\text { Jumlah Transaksi Mengandung A dan B }}{\text { Jumlah Transaksi Mengandung A }} \times 100
$$

Hasil perhitungan pada tabel 5. dengan nilai confidence diperoleh dengan sample perhitungan sebagai berikut :

$$
\begin{gathered}
\text { Confidence }=P(A \mid B)=\frac{\text { Jumlah Transaksi Mengandung A dan } B}{\text { Jumlah Transaksi Mengandung } A} \times 100 \\
\text { Confidence }=P(\text { Samsung A10 } \mid \text { Samsung M20 })=\frac{3}{13} \times 100=23 \%
\end{gathered}
$$

Setelah diperoleh nilai Confidence, maka diambil data itemset yang memenuhi minimum Confidence $=50 \%$ sebagai berikut.

Tabel 6. Pola kombinasi Dua Itemset yang memenuhi MinConfidence

\section{Hasil dan Pembahasan}

\section{Pengujian Aplikasi}

Pengujian data transaksi dilakukan dengan aplikasi data mining weka untuk mendapatkan rule yang dapat digunakan dalam mengambil keputusan. Pada saat dilakukan pengujian dengan weka maka langkah awal yang harus di persiapkan adalah data, untuk uraian data maka dimanfaatkan aplikasi Microsoft excel dengan penyimpanan dengan extension CSV (Comma Delimited), uraian gambar dibawah ini.

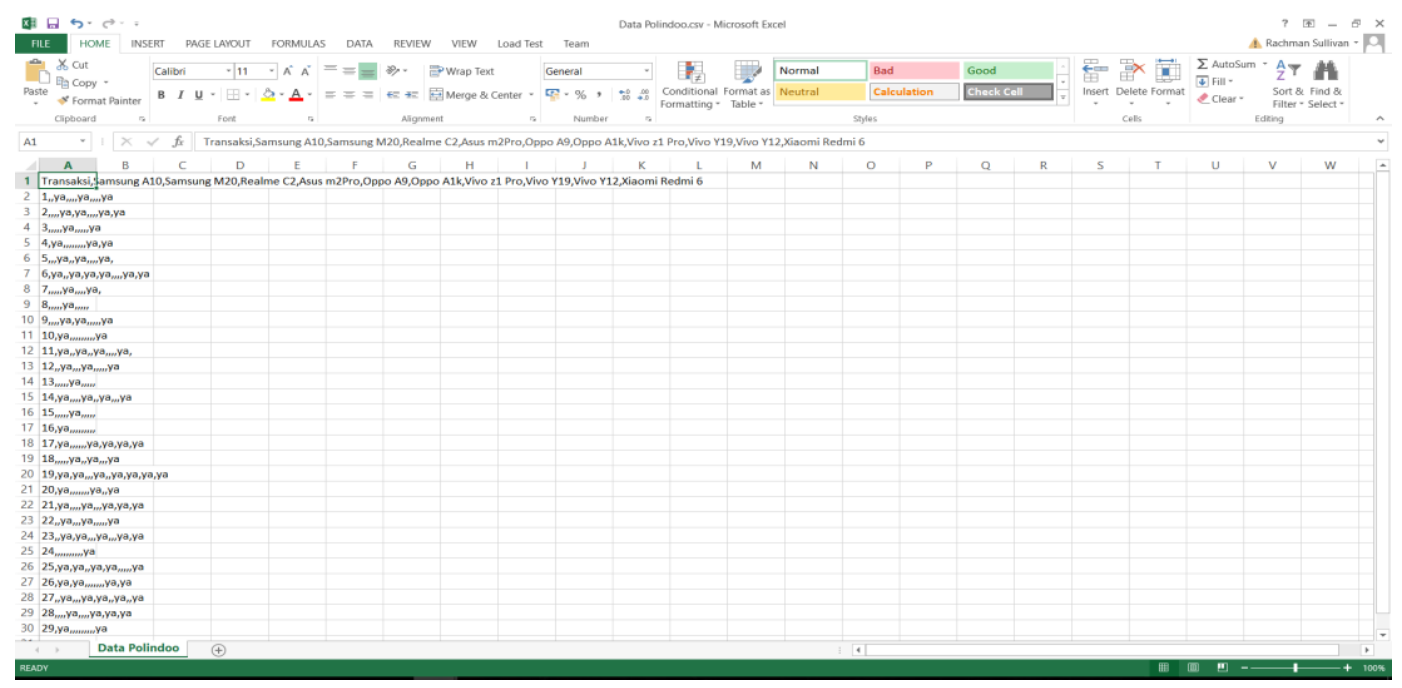

Gambar 2. Data CSV untuk transaksi penjualan 
Unitek : Jurnal Universal Teknologi

Vol. 14 No.2 Juli - Desember 2021

e-ISSN : 2580-2582, p-ISSN: 2089-3957

Kemudian dari data csv tersebut akan diinputkan kedalam aplikasi weka.

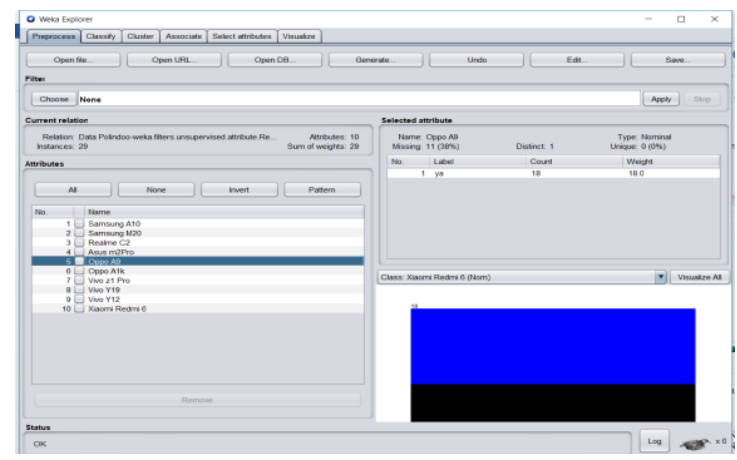

Gambar 3. Penginputan transaksi penjualan di aplikasi Weka

Pada saat gambar pemilihan data selesai maka secara otomatis fitur yang disediakan oleh weka sudah aktif yaitu classify, cluster, Associate dan yang lainnya. Untuk tahapan ini karena yang akan diselesaikan adalah apriori maka pilihan akfit adalah Associate. Setelah proses ini selesai maka pilih Choose dengan memilih apriori dan Tekan Tombol Start maka otomatis muncul analisa dari apriori seperti gambar berikut ini.

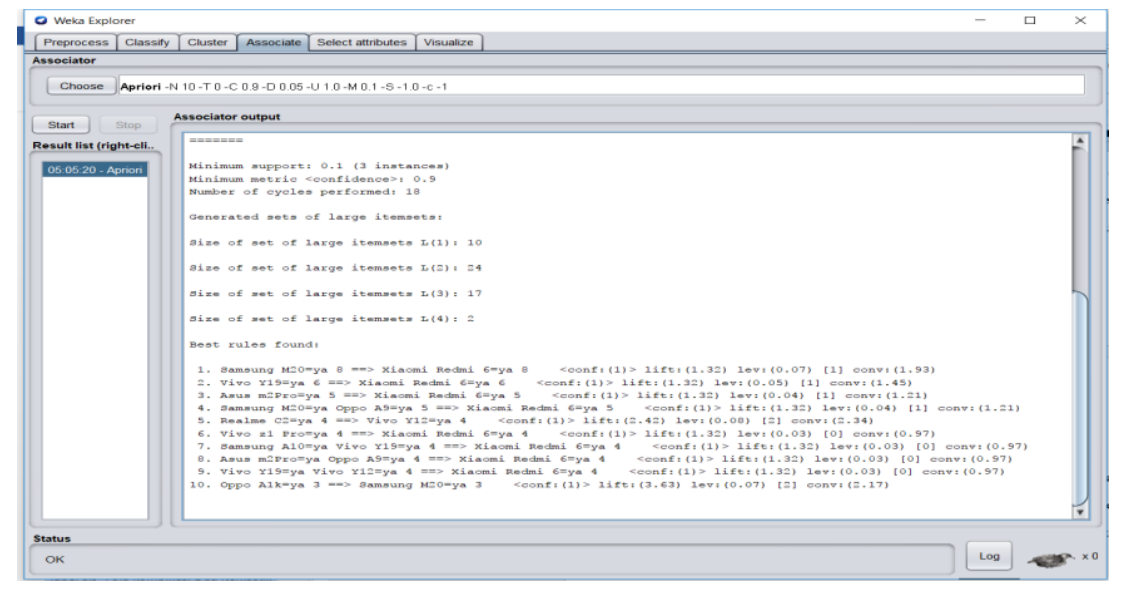

Gambar 4. Hasil pengujian di aplikasi Weka

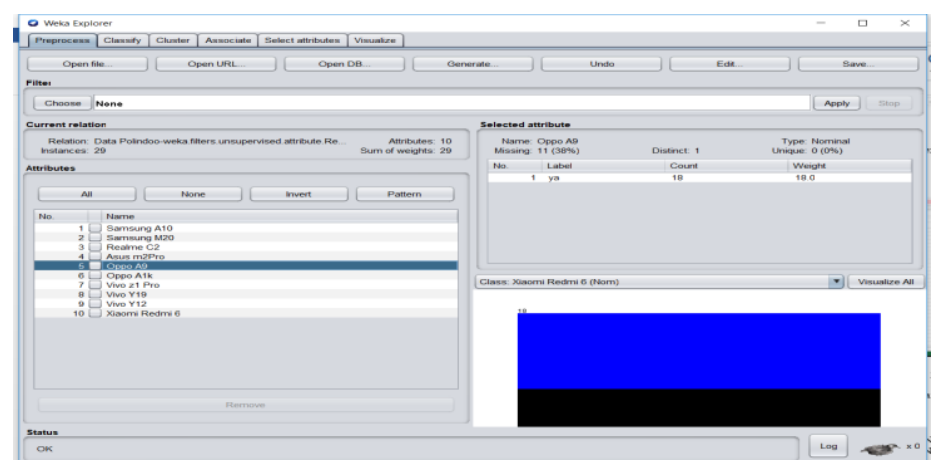

Gambar 5. Penginputan transaksi penjualan di aplikasi Weka 
Unitek : Jurnal Universal Teknologi

Vol. 14 No.2 Juli - Desember 2021

e-ISSN : 2580-2582, p-ISSN: 2089-3957

Maka hasil analisis yang diperoleh dari data 1 tahun dapat dilihat pada gambar 4.5 sebagai berikut.

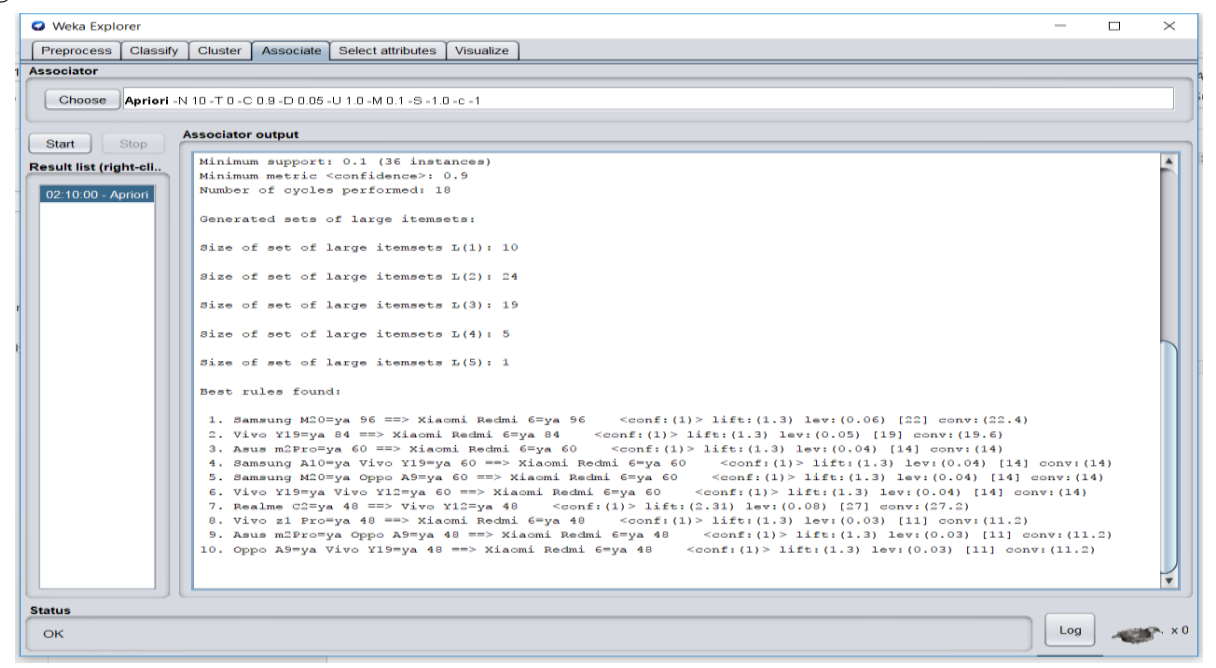

Gambar 6. Hasil pengujian di aplikasi Weka

Sehingga rule yang dihasilkan adalah sebagai berikut:

Scheme: $\quad$ weka.associations.Apriori -N 10 -T 0 -C 0.9 -D 0.05 -U 1.0 -M 0.1 -S -1.0 -

c - 1

Relation: Data Polindoo 1 tahun-weka.filters.unsupervised.attribute.Remove-R1

Instances: 360

Attributes: 10

Samsung A10

Samsung M20

Realme C2

Asus m2Pro

Oppo A9

Oppo A1k

Vivo z1 Pro

Vivo Y19

Vivo Y12

Xiaomi Redmi 6

$===$ Associator model (full training set) $===$

Apriori

Minimum support: 0.1 (36 instances)

Minimum metric < confidence>: 0.9

Number of cycles performed: 18

Generated sets of large itemsets:

Size of set of large itemsets L(1): 10

Size of set of large itemsets L(2): 24

Size of set of large itemsets L(3): 19

Size of set of large itemsets L(4): 5

Size of set of large itemsets L(5): 1 
Best rules found:

1. 1. Samsung M20=ya $96==>$ Xiaomi Redmi $6=$ ya 96 <conf:(1)> lift:(1.3) lev:(0.06) [22] conv:(22.4)

2. Vivo Y19=ya 84 ==> Xiaomi Redmi 6=ya 84 <conf:(1)> lift:(1.3) lev:(0.05) [19] conv:(19.6)

3. Asus m2Pro=ya $60==>$ Xiaomi Redmi 6=ya 60 <conf:(1)> lift:(1.3) lev:(0.04) [14] conv:(14)

4. Samsung A10=ya Vivo Y19=ya $60==>$ Xiaomi Redmi 6=ya 60 <conf:(1)> lift:(1.3) lev:(0.04) [14] conv:(14)

5. Samsung M20=ya Oppo A9=ya $60==>$ Xiaomi Redmi 6=ya $60<$ conf:(1)> lift:(1.3) lev:(0.04) [14] conv:(14)

6. Vivo Y19=ya Vivo Y12=ya $60==>$ Xiaomi Redmi 6=ya 60 <conf:(1)> lift:(1.3) lev:(0.04) [14] conv:(14)

7. Realme C2=ya $48==>$ Vivo Y12=ya 48 <conf:(1)> lift:(2.31) lev:(0.08) [27] conv:(27.2)

8. Vivo z1 Pro=ya 48 ==> Xiaomi Redmi 6=ya 48 <conf:(1)> lift:(1.3) lev:(0.03) [11] conv:(11.2)

9. Asus m2Pro=ya Oppo A9=ya $48==>$ Xiaomi Redmi 6=ya 48 <conf:(1)> lift:(1.3) lev:(0.03) [11] conv:(11.2)

10. Oppo A9=ya Vivo Y19=ya $48==>$ Xiaomi Redmi 6=ya 48 <conf:(1)> lift:(1.3) lev:(0.03) [11] conv:(11.2)

Kemudian berikut ini data csv untuk penjualan selama 2 tahun yang akan diinputkan kedalam aplikasi weka.

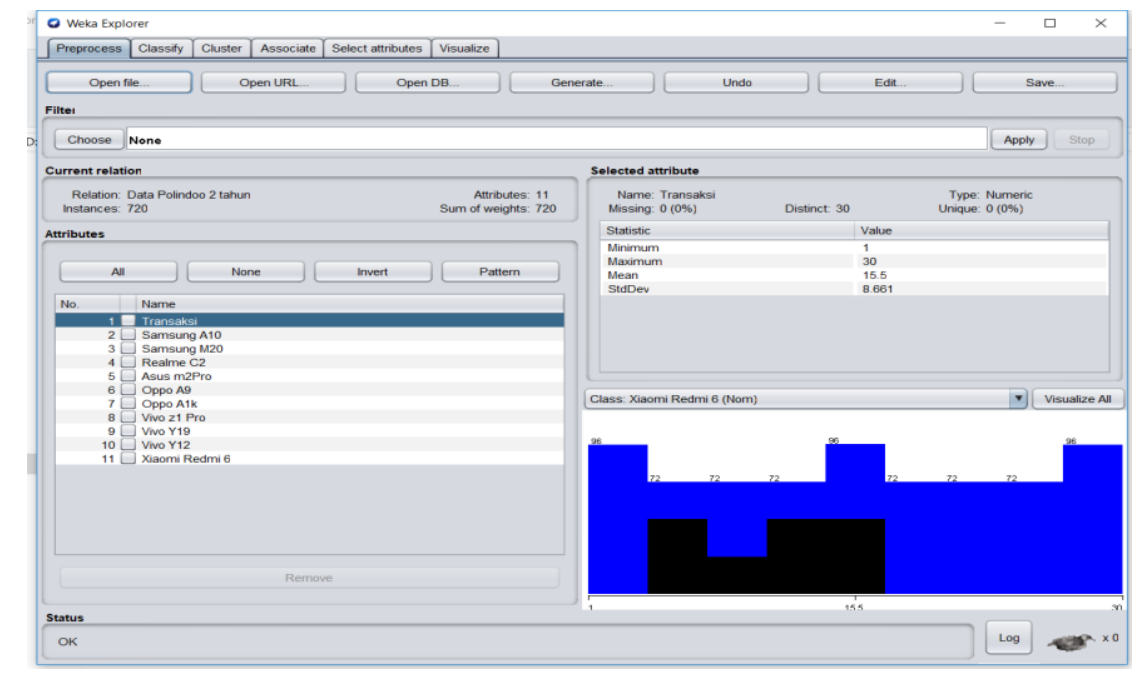

Gambar 7. Penginputan transaksi penjualan di aplikasi Weka

Berdasarkan hasil dari pengolahan data selama 2 tahun 720 data dengan menggunakan algoritma apriori seperti pada gambar 4.7.Dapat dijelaskan pola penjualan yang terbentuk di toko CV POLINDO yaitu.

1. Jika menjual samsung M20 maka kemungkinan pemilik toko juga menjual xiaomi redmi 6. memiliki tingkat confidance 1,3 yang artinya tingkat 
kepastian pemilik toko menjual samsung M20 dan xiaomi redmi 6 sangat tinggi dan sangat di minati

2. Jika menjual Vivo Y19 maka kemungkinan pemilik toko juga menjual xiaomi redmi 6. memiliki tingkat confidance 1,3 yang artinya tingkat kepastian pemilik toko menjual Vivo Y19 dan xiaomi redmi 6 sangat tinggi

3. Jika menjual Asus M2 Pro maka kemungkinan pemilik toko juga menjual xiaomi redmi 6 . memiliki tingkat confidance 1 yang artinya tingkat kepastian pemilik toko menjual Asus M2 Pro dan xiaomi redmi 6 sangat tinggi

4. Jika menjual samsung A10 dan Vivo Y19 maka kemungkinan pemilik toko juga menjual xiaomi redmi 6 . memiliki tingkat confidance 1 yang artinya tingkat kepastian pemilik toko menjual pola ini sangat tinggi

5. Jika menjual samsung M20 dan Oppo A9 maka kemungkinan pemilik toko juga menjual xiaomi redmi 6 . memiliki tingkat confidance 1 yang artinya tingkat kepastian pemilik toko menjual samsung M20,Oppo A9 dan xiaomi redmi 6 sangat tinggi

6. Jika menjual Vivo Y19 dan Vivo Y12 maka kemungkinan pemilik toko juga menjual xiaomi redmi 6 . memiliki tingkat confidance 1 yang artinya tingkat kepastian pemilik toko menjual Vivo Y19,Vivo Y12 dan xiaomi redmi 6 sangat tinggi

7. Jika menjual Realme $\mathrm{C} 2$ maka kemungkinan pemilik toko juga menjual Vivo Y12. memiliki tingkat confidance 1 yang artinya tingkat kepastian pemilik toko menjual Realme C2 dan Vivo Y12 sangat tinggi

8. Jika menjual Vivo Z1 Pro maka kemungkinan pemilik toko juga menjual xiaomi redmi 6 . memiliki tingkat confidance 1 yang artinya tingkat kepastian pemilik toko menjual Vivo Z1 Pro dan xiaomi redmi 6 sangat tinggi

9. Jika menjual Asus M2 Pro dan Oppo a9 maka kemungkinan pemilik toko juga menjual xiaomi redmi 6 . memiliki tingkat confidance 1 yang artinya tingkat kepastian pemilik toko menjual Asus M2 Pro,Oppo A9 dan xiaomi redmi 6 sangat tinggi

10. Jika menjual Oppo A9 dan Vivo Y19 maka kemungkinan pemilik toko juga menjual xiaomi redmi 6 . memiliki tingkat confidance 1 yang artinya tingkat kepastian pemilik toko menjual Oppo A9,Vivo Y19 dan xiaomi redmi 6 sangat tinggi dan banyak di minati 
Unitek : Jurnal Universal Teknologi

Vol. 14 No.2 Juli - Desember 2021

e-ISSN : 2580-2582, p-ISSN: 2089-3957

\section{Simpulan}

Berdasarkan analisa pada permasalahan yang terjadi dalam kasus yang diangkat tentang menentukan analisis terhadap penjualan pada handphone, mengatur stok dan melakukan strategi penjualan yang ada pada CV.Polindo, maka dapat ditarik kesimpulan sebagai berikut :

1. Dalam penerapan data mining dengan algoritma Apriori untuk menganalisa data penjualan produk handphone dan pengelolaan persediaan produk sehingga menjadi informasi yang berguna dilakukan dengan cara mencari atau mendefinisikan terlebih dahulu data-data transaksi terhadap produk yang terjual di CV.Polindo kemudian menghitung nilai frequensi penjualan produk dan mengolahnya kedalam algoritma Apriori.

2. Dari data tersebut biasa mendapatkan 10 rule asosiasi dan 720 data dengan nilai confidance yang berbeda.nilai confidance terbesar terdapat pada asosiasi di 2 itemset $1.3 \%$ yang menyebutkan bahwa jika menjual headphone Samsung m20 maka pemilik toko akan menjual xiaomi redmi 6

3. Tingkat support dan confidence / nilai kepastian dari data penjualan handphone diperoleh ketika data transaksi atau data penjualan telah diolah dengan algoritma Apriori. Semakin tinggi nilai support dan confidence-nya maka semakin erat pula keterkaitan produknya.

4. Data penjualan handphone dianalisa dengan menggunakan konsep Metode Association Rule untuk menemukan aturan asosiasi antara suatu kombinasi item dan membentuk pola kombinasi itemset atau produk yang terkait dengan bantuan algoritma Apriori.

5. Dalam merancang dan membangun aplikasi dengan menggunakan algoritma Apriori mengguanakan aplikasi berbasis Desktop pertama sekali yang dilakukan adalah pemodelan aplikasi yang dirancang dengan UML, setelah rancangan selesai, maka dilakukanlah tahap pengolahan data uji yang disebut preprocesing dalam data mining dan melakukan analisa data terhadap aplikasi WEKA. 


\section{Daftar Pustaka}

Ashraf, A., Anwer, S. and Gufran, M. (no date) 'A Comparative Study of Predicting Student's Performance by use of Data Mining Techniques', pp. 122-136.

Br Ginting, A. O. (2021) 'Penerapan Data Mining Korelasi Penjualan Spare Part Mobil Menggunakan Metode Algoritma Apriori (Studi Kasus: CV. Citra Kencana Mobil)', Journal of Information and Technology, 1(2), pp. 83-90. doi: 10.32938/jitu.v1i2.1472.

Ezhilarasan, C. and Ramani, S. (2018) 'Performance prediction using modified clustering techniques with fuzzy association rule mining approach for retail', Proceedings of 2017 International Conference on Intelligent Computing and Control, I2C2 2017, 2018-Janua, pp. 1-6. doi: 10.1109/I2C2.2017.8321777.

Jaya, I. and Hanadwiputra, S. (2021) 'Penerapan Algoritma Apriori Dalam Menentukan Strategi Persediaan Obat Terhadap Penjualan Obat Pada Apotek Karang Asih', Quality System Development, 11 No 1(2021-02-08), pp. 8-17.

Li, Z. et al. (2012) 'A framework for automatic TRIZ level of invention estimation of patents using natural language processing, knowledge-transfer and patent citation metrics', CAD Computer Aided Design. Elsevier Ltd, 44(10), pp. 9871010. doi: 10.1016/j.cad.2011.12.006.

Muchlis, M. M., Fitri, I. and Nuraini, R. (2021) 'Rancang Bangun Aplikasi Data Mining pada Penjualan Distro Bloods Berbasis Web menggunakan Algoritma Apriori', Jurnal JTIK (Jurnal Teknologi Informasi dan Komunikasi), 4(2), p. 26. doi: 10.35870/jtik.v5i1.197.

Sianturi, F. A., Informatika, T. and Utara, S. (2018) 'Penerapan Algoritma Apriori Untuk Penentuan Tingkat', 2(1), pp. 50-57.

Wahyuni, S., Saragih, kana S. and Perangin-angin, M. I. (2018) 'Implemntasi Metode Decision Tree C4.5 Untuk Menganalisa Mahasiswa Dop Out', ethos, 6(1), pp. $42-51$.

Wahyuni, S., Suherman and Harahap, K. P. (2018) 'Implementasi Data Mining dalam Memprediksi Stok Barang Menggunakan Algoritma Apriori’, 5, pp. 6771. doi: 10.31227/osf.io/nzk27.

Yu, Y. et al. (2019) 'Clinical big data and deep learning: Applications, challenges, and future outlooks', Big Data Mining and Analytics, 2(4), pp. 288-305. doi: 10.26599/BDMA.2019.9020007. 